\title{
Estimated Aerosol Health and Radiative Effects of the Residential Coal Ban in the Beijing-Tianjin-Hebei Region of China
}

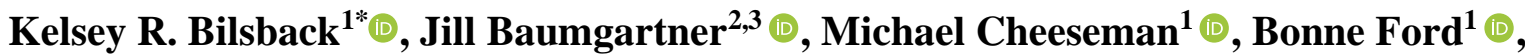 \\ John K. Kodros ${ }^{4} \oplus$, Xiaoying $\mathrm{Li}^{5}{ }^{\oplus}$, Emily Ramnarine ${ }^{1}$, Shu Tao ${ }^{6} \odot$, Yuanxun Zhang ${ }^{7,8} \odot$,

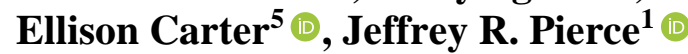

\author{
${ }^{1}$ Department of Atmospheric Science, Colorado State University, Fort Collins, CO, USA \\ ${ }^{2}$ Institute for Health and Social Policy, McGill University, Montreal, Quebec, Canada \\ ${ }^{3}$ Department of Epidemiology, Biostatistics and Occupational Health, McGill University, Montreal, Quebec, Canada \\ ${ }^{4}$ Institute of Chemical Engineering Sciences, ICE/FORTH, Patras, Greece \\ ${ }^{5}$ Department of Civil and Environmental Engineering, Colorado State University, Fort Collins, CO, USA \\ ${ }^{6}$ Laboratory for Earth Surface Processes, Sino-French Institute for Earth System Science, College of Urban and \\ Environmental Sciences, Peking University, Beijing, China \\ ${ }^{7}$ College of Resources and Environment, University of Chinese Academy of Sciences, Beijing, China \\ ${ }^{8}$ CAS Center for Excellence in Regional Atmospheric Environment, Chinese Academy of Sciences, Xiamen, China
}

\begin{abstract}
Particle-phase air pollution is a leading risk factor for premature death globally and impacts climate by scattering or absorbing radiation and changing cloud properties. Within the Beijing-Tianjin-Hebei region of China, where there are severe air quality problems, several municipalities have begun implementing a coal-to-electricity program that bans residential coal and provides subsidies for electricity and electric-powered heat pumps. We used GEOS-Chem to evaluate two complete residential coal-to-electricity transitions - a Beijing-off scenario and Beijing-Tianjin-Hebei-off scenario-each relative to a base case. We estimate that within China, the ambient fine particulate matter $\left(\mathrm{PM}_{2.5}\right)$ reductions in the Beijing-off scenario could lead to 1,900 (95\% CI: 1,200-2,700) premature deaths avoided annually, while the Beijing-Tianjin-Hebei-off scenario could lead to 13,700 (95\% CI: 8,900-19,600) premature deaths avoided annually. Additionally, we estimate that the residential-coal-ban scenarios will result in a positive top-of-the-atmosphere aerosol direct radiative effect (DRE) (model domain average: Beijing-off: $0.023 \mathrm{~W} \mathrm{~m}^{-2}$; Beijing-Tianjin-Hebei-off: $0.30 \mathrm{~W} \mathrm{~m}^{-2}$ ) and a negligible cloud-albedo aerosol indirect effect (AIE) (Beijing-off: $0.0001 \mathrm{~W} \mathrm{~m}^{-2}$; Beijing-Tianjin-Hebei-off: $0.0027 \mathrm{~W} \mathrm{~m}^{-2}$ ). To evaluate the uncertainty of the radiative effects, we calculated the DRE under four black-carbon mixing-state assumptions and both the DRE and AIE assuming three different black-carbon-to-organic-aerosol (BC:OA) ratios for residential-coal emissions. Although the magnitude of our radiative forcing estimates varied across sensitivity cases, the domain average remained positive. When only considering the aerosol-related effects of the aforementioned coal-ban scenarios, we predict substantial health benefits, but do not anticipate a climate "co-benefit", because removing aerosol emissions leads to a warming tendency. However, if the coal-to-electricity program results in less net greenhouse gas emissions due to the replacement heaters, the policy may be able to achieve health and climate "co-benefits".
\end{abstract}

Keywords: Air pollution; Radiative forcing; $\mathrm{PM}_{2.5}$-related mortality; Residential emissions.

\section{INTRODUCTION}

The Beijing-Tianjin-Hebei region of China is one of the most highly-polluted regions in the world (Chan and Yao, 2008; Zhang et al., 2015; Zhang and Cao, 2015). In recent

\footnotetext{
* Corresponding author.

E-mail address: Kelsey.Bilsback@ colostate.edu
}

decades, rapid economic growth coupled with industrialization and urbanization has resulted in fine particulate matter $\left(\mathrm{PM}_{2.5}\right)$ levels that exceed the air-quality guidelines of both the Chinese government $\left(35 \mu \mathrm{g} \mathrm{m}^{-3}\right)$ and the World Health Organization $\left(10 \mu \mathrm{g} \mathrm{m}^{-3}\right)$ in the region (Ma et al., 2014; Zhang and Cao, 2015). Stagnant meteorological conditions in the Beijing-Tianjin-Hebei region also lead to severe haze episodes, where hourly $\mathrm{PM}_{2.5}$ levels may exceed $600 \mu \mathrm{g} \mathrm{m}^{-3}$ (Wang et al., 2014). The 2017 Global Burden of Disease (GBD) Study estimated that exposure to ambient $\mathrm{PM}_{2.5}$ is a 
leading risk factor for premature death in China, resulting in more than 1.2 million premature deaths per year (Stanaway et al., 2018). Additionally, high aerosol burdens in the atmospheric column impact the local atmospheric radiative budget, because aerosols can directly scatter (e.g., sulfate, organic aerosol (OA)) and absorb radiation (e.g., black carbon (BC)) (i.e., the aerosol direct radiative effect (DRE)) and change cloud properties by influencing the number of cloudcondensation nuclei (i.e., the cloud-albedo aerosol indirect effect (AIE)) (Stocker et al., 2013).

In the Beijing-Tianjin-Hebei region, during the winter, many households burn unprocessed coal in built-in boiler stoves used for space heating (Fig. S1). These residential coal stoves have much higher particle-phase emissions than coal from the industrial and power sectors, because residential coal is burned under poor combustion conditions and the residential coal stoves do not have emissions controls (Streets et al., 2001). Due in part to emissions from residential coal use and stagnant meteorological conditions, the BeijingTianjin-Hebei region often has high air pollution levels during the winter (Ma et al., 2014; Zhang and Cao, 2015). Recently, to combat air quality issues, several municipalities in the Beijing-Tianjin-Hebei region of China have been rolling out coal-to-electricity policies, which ban residential coal and provide subsidies for the purchase and installation of electric-powered heat pumps in place of coal-heating stoves (National Development and Reform Commission, 2017; Barrington-Leigh et al., 2019). In addition to the coalto-electricity policies, smaller coal-to-natural-gas policies are also being rolled out in some regions. These coal-toelectricity policies are being implemented at the villagelevel with new villages being added each winter. The energy program began in 2016/2017 with the rollout anticipated to continue beyond 2020/2021 and is part of a longer term plan that would ultimately ban residential use of coal for space heating across northern China. These household-energy policies are part of a larger rollout of clean air policies in China (Zheng et al., 2018).

Several previous modeling studies have looked at how emissions from residential coal heating impacts ambient air quality. These studies estimate that between 20 and $65 \%$ of ambient $\mathrm{PM}_{2.5}$ in Beijing-Tianjin-Hebei comes from residential coal heating, depending on emissions and atmospheric conditions (Liu et al., 2016; Xue et al., 2016; Zhang et al., 2017; Meng et al., 2019). Archer-Nicholls et al. (2016) and Archer-Nicholls et al., (2019) estimated the health and radiative effects, respectively, of all residential biomass and coal use across China. Shen et al. (2019) investigated the health and climate impacts of transitions in residential energy across China between 1992 and 2012. Liu et al. (2019) investigated the health impacts, but not the climate impacts, of the planned residential coal policies between 2010 and 2030 in Beijing-Tianjin-Hebei, using a sourcereceptor model, which used a statistical approach to estimate changes in $\mathrm{PM}_{2.5}$ rather than perturbing the model directly. To the best of our knowledge, no studies have examined both the aerosol health and radiative impacts of the coal-toelectricity policies that are currently ( 2016-2020) being implemented in Beijing-Tianjin-Hebei using a chemical- transport model. Importantly, our study is complementary to, but distinct from, other recent studies that have investigated the aerosol health and climate impacts of the residential sector across China prior to the current coal-to-electricity policies or used different approaches for representing the atmospheric changes.

To address these gaps, we used GEOS-Chem, a chemicaltransport model, to quantify the air quality, health, and radiative impacts of two complete residential coal-to-electricity transitions - a Beijing-off scenario and a Beijing-TianjinHebei-off scenario. We estimate the number of premature mortalities that could be averted from both of these scenarios using an integrated-exposure-response (IER) function (Burnett et al., 2014). Additionally, we estimate the top-ofthe-atmosphere aerosol DRE and cloud-albedo AIE. Given the dependence of our radiative forcing estimates on aerosol properties, we calculate the DRE under four black-carbon mixing-state assumptions and both the DRE and AIE under three different black-carbon-to-organic-aerosol (BC:OA) ratios for residential-coal emissions. Then, to constrain the modeled aerosol properties, we compare single scattering albedo (SSA) measurements, which depend on black-carbon mixing state and aerosol composition, from the Aerosol Robotic Network (AERONET) to the SSA estimates under each sensitivity case.

\section{METHODS}

\section{Model Configuration}

We used (GEOS-Chem v12.0.3; The International GEOSChem User Community, 2018) (http://www.geos-chem.org) to simulate aerosol size and composition. Table 1 describes the six simulations used in this study. GEOS-Chem was driven by GEOS Forward Processing offline meteorological fields (GEOS-FP; https://gmao.gsfc.nasa.gov/). We ran regional simulations at $0.25^{\circ} \times 0.3125^{\circ}$ resolution with 47 vertical layers. The model domain spanned $109.062^{\circ}-132.1875^{\circ} \mathrm{E}$ longitude; $29.250^{\circ}-44.000^{\circ} \mathrm{N}$ latitude, which included Beijing, Tianjin, and Hebei and several surrounding provinces (Fig. S2). Regional boundary conditions were generated using global simulations at $4^{\circ} \times 5^{\circ}$ with 47 vertical layers. The regional simulations were run with 10 days of spin up while the global simulations were run with one month of spin up.

Anthropogenic emissions in Asia, including residential coal, were from the MIX 2010 inventory (Li et al., 2017). Other emissions inventories are described in Note S1. We used two different model configurations to estimate the effects of the residential-coal-ban scenarios. The health effect calculations were run using a simplified version of the GEOS-Chem model that focuses on aerosol mass rather than gases or aerosol size distributions, because the mortality calculations required annual $\mathrm{PM}_{2.5}$ concentrations. The radiative effect calculations require details about the aerosol size distribution, and hence, more-comprehensive GEOSChem simulations. Due to the computational burden of the simulations with size distributions, we only performed the radiative forcing calculations during the winter months (December through February). We chose to model these three months, because emissions from residential coal were 
Table 1. Summary of GEOS-Chem simulations. To estimate the aerosol-related health effects, we ran the GEOS-Chem bulk-aerosol (i.e., "aerosol-only") configuration, and to estimate the aerosol-related climate effects, we ran the GEOS-ChemTOMAS configuration for the winter. The health-effect calculations required longer simulation times (i.e., one year); therefore, due to computational constraints, we did not include online chemistry/aerosol microphysics in these simulations.

\begin{tabular}{|c|c|c|c|}
\hline Name & Scenarios & Simulation type & Simulation time \\
\hline Base case & $\begin{array}{l}\text { Continued residential coal } \\
\text { use }\end{array}$ & $\begin{array}{l}\text { Online chemistry/ aerosol } \\
\text { microphysics }\end{array}$ & $\begin{array}{l}\text { One year } \\
\text { (Dec 2014-Nov } 2015 \text { or } \\
\text { Dec 2015-Nov 2016) } \\
\text { Three months } \\
\text { (Dec 2014-Feb } 2015 \text { or } \\
\text { Dec 2015-Feb 2016) }\end{array}$ \\
\hline Beijing-off & $\begin{array}{l}\text { Residential coal ban in } \\
\text { Beijing only }\end{array}$ & $\begin{array}{l}\text { Bulk aerosol } \\
\text { Online chemistry/ aerosol } \\
\text { microphysics }\end{array}$ & $\begin{array}{l}\text { One year } \\
\text { (Dec 2014-Nov } 2015 \text { or } \\
\text { Dec 2015-Nov 2016) } \\
\text { Three months } \\
\text { (Dec 2014-Feb } 2015 \text { or } \\
\text { Dec 2015-Feb 2016) }\end{array}$ \\
\hline Beijing-Tianjin-Hebei-off & $\begin{array}{l}\text { Residential coal ban in } \\
\text { Beijing-Tianjin-Hebei }\end{array}$ & $\begin{array}{l}\text { Bulk aerosol } \\
\text { Online chemistry/ aerosol } \\
\text { microphysics }\end{array}$ & $\begin{array}{l}\text { One year } \\
\text { (Dec 2014-Nov } 2015 \text { or } \\
\text { Dec 2015-Nov 2016) } \\
\text { Three months } \\
\text { (Dec 2014-Feb } 2015 \text { or } \\
\text { Dec 2015-Feb 2016) }\end{array}$ \\
\hline
\end{tabular}

lower outside of these three months, according to the MIX 2010 emissions inventory. The two model configurations are described in the following two paragraphs and outlined in Table 1.

To estimate the health effects, we used the GEOS-Chem bulk-aerosol configuration that has offline oxidation fields and explicitly includes bulk aerosol tracers (sulfate, ammonium, nitrate, sea salt, $\mathrm{OA}, \mathrm{BC})$ and aerosol-precursor vapors $\left(\mathrm{SO}_{2}\right.$, $\mathrm{NH}_{3}$ ). Each bulk-aerosol simulation was run for 12 months (December-November) to simulate annually averaged $\mathrm{PM}_{2.5}$; the equation used to estimate $\mathrm{PM}_{2.5}$ can be found in Note S2. A comparison of $\mathrm{PM}_{2.5}$ estimates from both model configurations is in Fig. S3. We simulated two years prior to the implementation of the coal ban (December 2014November 2015 and December 2015-November 2016). The anthropogenic emissions from the MIX inventory were not changed between the two winters. Differences between the two years are small, e.g., $2.7 \%$ averaged across the simulation domain. So, throughout the paper, we present the results as an average of the two winters. Figures showing the differences between the simulations are in the SI (Fig. S4).

To estimate the radiative effects, we ran simulations using GEOS-Chem's full tropospheric chemistry ("tropchem") setup with TwO Moment Aerosol Sectional (TOMAS) online aerosol microphysics (Table 1), which has 15 size sections ranging from $3 \mathrm{~nm}$ to $10 \mu \mathrm{m}$ (Adams and Seinfeld, 2002; Trivitayanurak et al., 2008; Kodros and Pierce, 2017). Sizeresolved aerosol species include sulfate, sea salt, OA, BC, and dust. Ammonium and nitrate were not size resolved in the model, so we assumed that they followed the size distribution for aerosol water. Therefore, ammonium and nitrate increased particle size, but not number. TOMAS includes nucleation, condensation, and coagulation aerosol microphysics processes as well as size-resolved emissions, dry and wet deposition, and aqueous sulfur chemistry. These simulations were only run for the winter heating months (December-February). For each scenario, we simulated two different winters (December 2014-February 2015 and December 2015-February 2016); however, the results are presented as a two-winter average throughout the paper and differences between the two simulations are presented in the SI (Figs S5 and S6).

For each of the two GEOS-Chem setups, we simulated three scenarios to estimate the impacts of a complete residential coal ban (Table 1). For the "Base-case" scenario, residential-coal emissions rates were held fixed throughout the domain; for the "Beijing-off" scenario, residential-coal emissions rates were set to zero in the province of Beijing; and for the "Beijing-Tianjin-Hebei-off" scenario, residential coal emissions rates were set to zero in the provinces of Beijing, Tianjin, and Hebei. Aerosol-relevant species that were set to zero included: $\mathrm{BC}, \mathrm{OC}, \mathrm{SO}_{2}, \mathrm{SO}_{4}$. (The masked areas within our grid scheme are shown in Fig. S2.) Most emissions from the residential sector in Beijing-Tianjin-Hebei are from residential coal combustion (Zhang et al., 2017), thus zeroing out all emissions from the residential sector, although an upper limit, is still likely to be a good approximation for eliminating residential coal use. We note that we did not account for how the increased electricity generation will impact aerosol emissions in the region. However, we expect the centralized electricity generation to have much lower aerosol emissions than residential coal used for space heating.

\section{Health Effects}

$\mathrm{PM}_{2.5}$-related premature mortalities were calculated using the GBD 2010 framework and results from the GEOS-Chem bulk-aerosol model. Mortalities were only calculated within China. We used the Gridded Population of the World (GPWv4.11) from the NASA Socioeconomic Data and 
Application Center (SEDAC; https://sedac.ciesin.columbia. edu/) from the year 2015. The population data was downloaded at $0.25^{\circ} \times 0.25^{\circ}$ resolution and regridded to the model resolution. Country-level baseline mortality rates in China for lung cancer, ischemic heart disease, stroke, and chronic obstructive pulmonary disease were obtained from the Institute for Health Metrics and Evaluation (IHME; http://www.healthdata.org/gbd) from the year 2015.

We used IER functions from Burnett et al. (2014) to relate ambient $\mathrm{PM}_{2.5}$ exposure to increased risk of premature mortality from each disease. Burnett et al. (2014) reports 1,000 sets of coefficients for each IER that were fit using a Monte Carlo approach. We used these model fits to estimate the mean and $95 \%$ confidence interval of mortality from each disease. Uncertainties in the IER are discussed in previous work (Ford and Heald, 2016; Kodros et al., 2018; Nethery and Dominici, 2019).

We calculated $\mathrm{PM}_{2.5}$-related premature mortalities using two methods (Kodros et al., 2016a). First, we subtracted the number of $\mathrm{PM}_{2.5}$-related mortalities of either Beijing-off of Beijing-Tianjin-Hebei-off scenario from the base-case scenario (Subtraction Method). Second, we multiplied the fraction of total $\mathrm{PM}_{2.5}$ from residential coal by the total number of $\mathrm{PM}_{2.5}$-related mortalities from all air pollution sources (Attribution Method). Due to the nonlinear nature of the IER functions (where the change in relative risk decreases as $\mathrm{PM}_{2.5}$ concentrations increase), the reduction depends on the starting point and thus two methods yield different estimates. The Subtraction Method is likely more representative of the potential health benefits (that are possible to estimate) associated with eliminating an emissions source, such as in the case of the residential-coal ban. The Attribution Method, on the other hand, allows the total $\mathrm{PM}_{2.5}$-related mortalities to be attributed to specific sources (the sum of all source contributions equal the total $\mathrm{PM}_{2.5}$-related mortalities, which is not the case for the subtraction method).

\section{Direct Radiative Effect and Cloud-albedo Aerosol Indirect Effect}

We used an offline version of the Rapid Radiative Transfer Model for Global and Regional Model Applications (RRTMG; Iacono et al., 2008) to calculate the top-of-theatmosphere all-sky DRE and AIE. Comprehensive details of the calculations are provided in previous work (Kodros et al., 2016b; Kodros and Pierce, 2017; Ramnarine et al., 2019). Briefly, we used monthly mean aerosol mass and number concentrations (GEOS-Chem-TOMAS), surface albedo from the Satellite Application Facility on Climate Monitoring (Karlsson et al., 2017), and other meteorological variables from GEOS-FP. For the DRE, we calculated the aerosol optical depth (AOD), single scattering albedo (SSA), and asymmetry parameter for each model grid box using Mie theory or core-shell Mie theory (Bohren and Huffman, 1983) and refractive indices from the Global Aerosol Database (Koepke et al., 1997). For the AIE, we calculate the change in cloud albedo using the cloud-drop-radius perturbation method that has been published previously (Rap et al., 2013; Scott et al., 2014; Kodros et al., 2016b).

The aerosol radiative effects calculated here are sensitive to both the aerosol mixing state and the amount of strongly absorbing (e.g., BC) and weakly absorbing (e.g., OA) aerosol (Bond et al., 2006; Cappa et al., 2012; Kodros et al., 2015). To examine these sensitivities, we ran fifteen radiative forcing calculations for each scenario with different assumptions about the aerosol mixing state and different $\mathrm{BC}$ :OA emissions ratios (keeping total aerosol mass constant) from the residential-coal sector (Table 2). For the DRE, we tested four mixing-state assumptions: an external mixing state and three internal mixing states (i.e., Maxwell Garnett, coreshell, and volume). These mixing-state assumptions are a

Table 2. Summary of radiative-forcing sensitivity cases. Both the direct radiative effect (DRE) and the cloud-albedo aerosol indirect effect (AIE) were tested under three emissions sensitivity cases including: the base BC/OA case, where the black carbon (BC):organic aerosol (OA) ratios were from the MIX v2010 inventory; the high-BC/low-OA case, where the BC:OA ratio from the base case was doubled; and the low-BC/high-OA case, where the $\mathrm{BC}: \mathrm{OA}$ ratio from the base case was halved. Four mixing-state assumptions were tested for the DRE including: one external mixing state and three internal mixing states (i.e., Maxwell Garnett, core-shell, and volume).

\begin{tabular}{lll}
\hline Radiative effect & Emissions case & Mixing state \\
\hline DRE & Base BC/OA & External \\
DRE & Base BC/OA & Maxwell-Garnett internal \\
DRE & Base BC/OA & Core-shell internal \\
DRE & Base BC/OA & Volume internal \\
DRE & High BC/Low OA & External \\
DRE & High BC/Low OA & Maxwell-Garnett internal \\
DRE & High BC/Low OA & Core-shell internal \\
DRE & High BC/Low OA & Volume internal \\
DRE & Low BC/High OA & External \\
DRE & Low BC/High OA & Maxwell-Garnett internal \\
DRE & Low BC/High OA & Core-shell internal \\
DRE & Low BC/High OA & Volume internal \\
AIE & Base BC/OA & N/A \\
AIE & High BC/Low OA & N/A \\
AIE & Low BC/High OA & N/A \\
\hline
\end{tabular}


useful tool for estimating the bounds of the aerosol radiative forcing. All aerosol components except BC were always assumed to be homogeneously internally mixed within each size section. For the "external" mixing state, we assumed BC and the more-scattering species in each size section were in separate particles of the same size. For the "Maxwell-Garnett" internal mixing state (Garnett, 1904), we assumed that BC spheres were randomly distributed within the homogenous particle composed of the more-scattering components. For the "core-shell" internal mixing state, we assumed that BC was a pure core within a homogeneous shell made up of the more-scattering components. For the "volume" internal mixing state, we assumed that all aerosol species (including BC) were mixed homogeneously. Across all mixing-state assumptions, we assumed OA was not greatly absorptive (i.e., did not contain appreciable brown carbon).

For both the DRE and the AIE, we tested three sensitivity cases where we varied the $\mathrm{BC}$ :OA ratio of emissions from the residential sector (Table 2). For the "base-BC/OA" case, we maintained the $\mathrm{BC}$ :OA ratios from the MIX 2010 emissions inventory (Fig. S7). For the "high-BC/low-OA" scenario, we doubled the $\mathrm{BC}$ :OA ratios, while for the "low$\mathrm{BC} /$ high-OA" scenario, we halved the $\mathrm{BC}$ :OA ratios. Across all cases, the total mass and number in each size section were conserved. The aerosol concentrations for these cases were calculated offline using the equations provided in Note S3. $\mathrm{SO}_{2}$ was not modified in the $\mathrm{BC}: \mathrm{OA}$ sensitivity cases.

\section{Model Evaluation}

The models were evaluated by several statistical metrics including: slope, coefficient of determination $\left(\mathrm{R}^{2}\right)$, mean bias (MB), mean error (ME), mean normalized bias (MNB), mean normalized error (MNE), and normalized mean bias (NMB). (Equations for calculating the biases and errors are provided in Note S4). Annually averaged $\mathrm{PM}_{2.5}$ estimates from the GEOS-Chem bulk-aerosol model configuration were evaluated against 651 surface monitors. (Map shown in Fig. S8). The data were downloaded from the Harvard Dataverse (Berman, 2017) that mirrored data published on https://beijingair.sinaapp.com/, which was collected by the China National Environmental Monitoring Center (CNEMC; http://www.cnemc.cn/) and the Beijing Municipal Environmental Monitoring Center (BMEMC, http://www.b jmemc.com.cn/). Measurements were made with either the tapered element oscillating microbalance (TEOM) or betaattenuation (BAM) method. Hourly measurements were excluded from the monthly average if (1) the coarse particulate matter $\left(\mathrm{PM}_{10}\right)$ measurement was less than $\mathrm{PM}_{2.5}$, (2) either the $\mathrm{PM}_{10}$ or $\mathrm{PM}_{2.5}$ measurement was missing for a particular hour, or (3) a value was repeated more than four times. Monthly averages were excluded if more than $25 \%$ of the data were missing over the course of a month (after the other data cleaning procedures were completed). Monthly averages were averaged annually and compared with $\mathrm{PM}_{2.5}$ surface estimates from the GEOS-Chem bulk-aerosol model. Only model months that corresponded to months where observations met the criteria, above, were included in the annual average in our plots specific to model evaluation. After data cleaning, $96.6 \%$ of all possible monthly averages remained for validation. All monitors within the same model grid cell were also averaged to a single value when compared to the GEOS-Chem model output.

For a second comparison, annually averaged $\mathrm{PM}_{2.5}$ estimates from the GEOS-Chem bulk-aerosol model configuration were also compared to China Regional $\mathrm{PM}_{2.5}$ estimates (V4.CH.02) developed by the Atmospheric Composition Analysis Group (http://fizz.phys.dal.ca/ atmos/martin/?page_id=140). These estimates were developed using the geoscience-based approach of van Donkelaar et al. (2019). The $\mathrm{PM}_{2.5}$ estimates are provided at $0.1^{\circ} \times 0.1^{\circ}$ resolution and, while the van Donkelaar et al. (2019) estimates cannot be considered the true $\mathrm{PM}_{2.5}$ values for each location, they combine data from satellites, chemical transport models, and ground measurements, which may allow for better estimates than model data alone. We compared model $\mathrm{PM}_{2.5}$ estimates averaged over both simulation years (December 2014-November 2016) to $2015 \mathrm{PM}_{2.5}$ estimates from van Donkelaar et al. (2019), which were regridded to the GEOS-Chem model resolution $\left(0.25^{\circ} \times 0.3125^{\circ}\right)$.

The AOD and SSA estimates from GEOS-Chem-TOMAS were compared to measurements from AERONET monitoring sites (Holben et al., 1998; Sinyuk et al., 2007). Seven sites were used in the comparison. (Map shown in Fig. S9.) We compared the model output to Level 1.5 measurements from AERONET, which include automated quality controls and cloud screening (Smirnov et al., 2000). We linearly interpolated instantaneous hourly model output to the time when the AERONET measurements were taken and compared the model and measurements at $440 \mathrm{~nm}$. The AERONET data was compared to model SSA under the sensitivity cases (discussed in the "Direct radiative effect and cloud-albedo aerosol indirect effect" section).

\section{RESULTS AND DISCUSSION}

\section{PM2.5-related Health Effects of the Residential Coal Ban Modelled and Measured PM 2.5}

In the Base-case scenario, the average $\mathrm{PM}_{2.5}$ surface concentration in the simulation domain was $54.6 \mu \mathrm{g} \mathrm{m}^{-3}$ (interquartile range (IQR): $30.5-78.4 \mu \mathrm{g} \mathrm{m}^{-3}$ ) (Fig. 1). The highest $\mathrm{PM}_{2.5}$ concentrations tended to be in Beijing and southward through Hebei, Shandong, and Henan, while the lowest $\mathrm{PM}_{2.5}$ concentrations tended to be to the northwest Beijing in the northern portion of Hebei and in Inner Mongolia. This spatial pattern exists because the region south of Beijing has a higher population density and higher emissions rates compared to the mountainous regions to the northwest of Beijing that has a smaller population and fewer emissions sources. (See Fig. S10 (emissions map) and Fig. S11 (population density map)). Further, this region to the south of Beijing can have low-speed south to southwest winds that also contribute to air pollution build-up to the south of Beijing-Tianjin-Hebei during the winter (Wang et al., 2014).

The $\mathrm{R}^{2}$ between the $\mathrm{PM}_{2.5}$ measurements and the $\mathrm{PM}_{2.5}$ estimates from GEOS-Chem is 0.56, although the model tends to have a positive bias (NMB: 35.7\%) (Fig. 2). The model is similarly correlated $\left(\mathrm{R}^{2}: 0.58\right)$ and positively biased (NMB: $53.6 \%$ ) compared to the $\mathrm{PM}_{2.5}$ estimates from van 

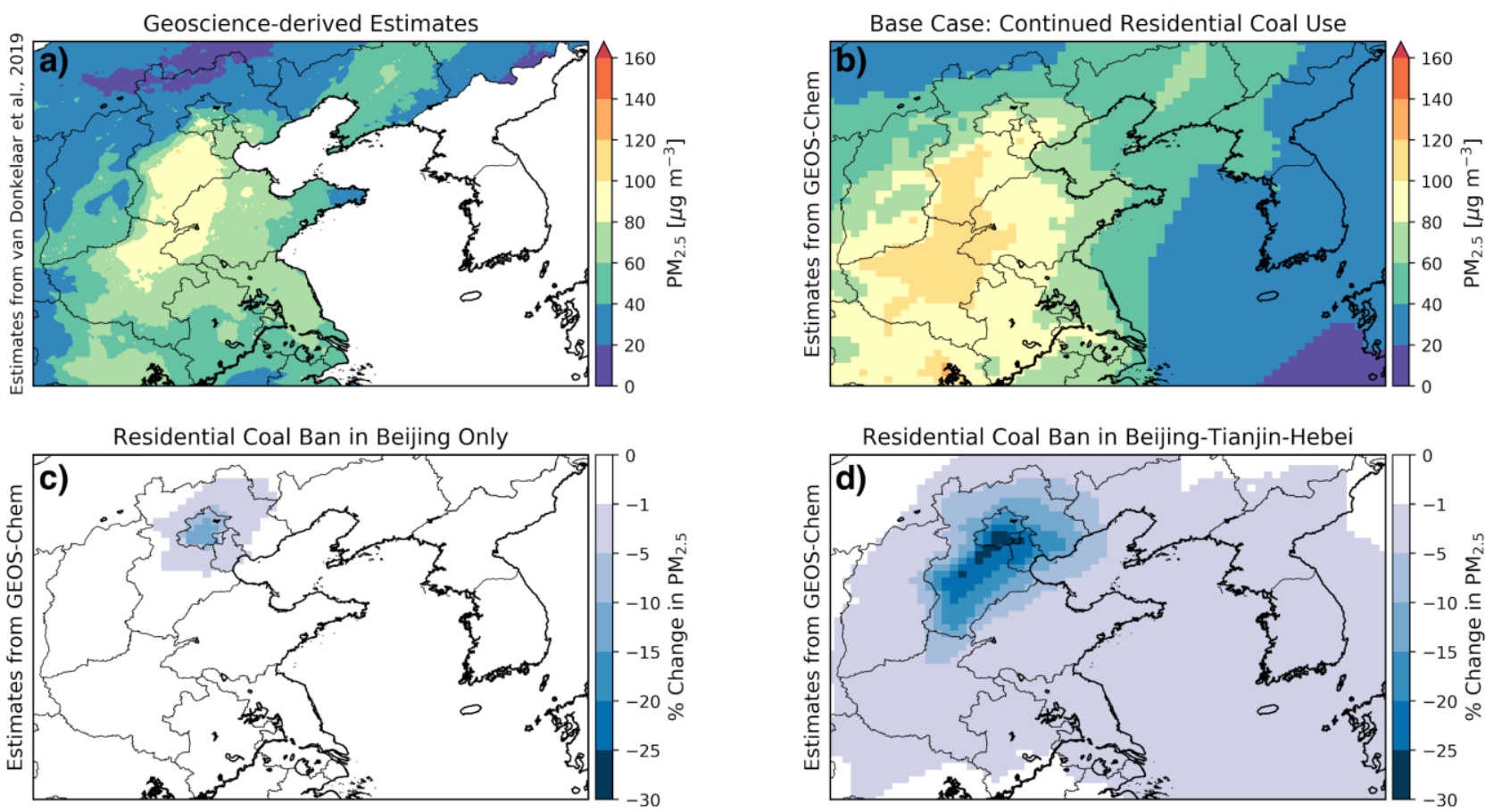

Fig. 1. Surface fine particulate matter $\left(\mathrm{PM}_{2.5}\right)$ from van Donkelaar et al. (2019) for the year 2015 (panel a) and the GEOSChem bulk-aerosol model configuration (panels b, c, and d). In panel b, the continued-residential-coal-use simulation (base case) is given as an absolute mass concentration, while the coal-ban scenarios (Beijing-off in panel c and Beijing-TianjinHebei-off in panel d) are given as a percentage-change relative to the continued-residential-coal-use simulation (base case). Results from the GEOS-Chem bulk-aerosol model configuration (panel b, c, and d) are averaged across two simulations years (December 2014 through November 2016).
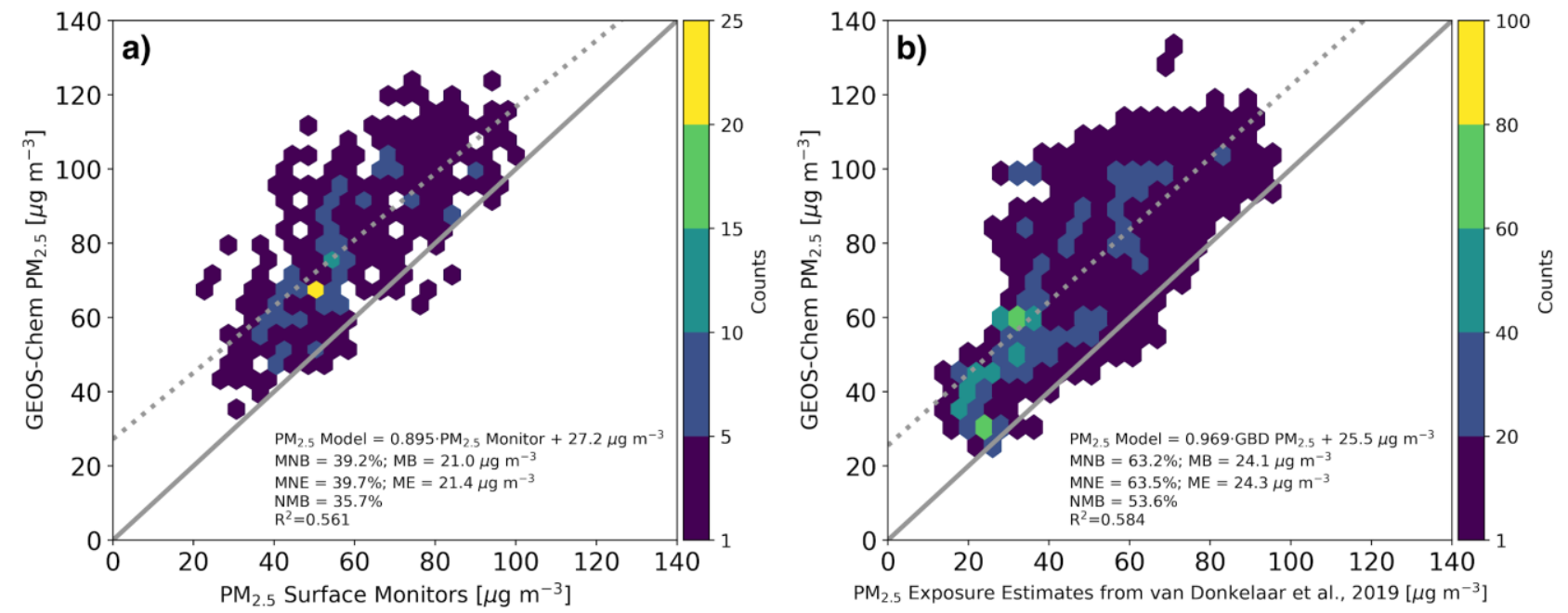

Fig. 2. Fine particulate matter $\left(\mathrm{PM}_{2.5}\right)$ surface measurements versus GEOS-Chem $\mathrm{PM}_{2.5}$ estimates (panel a) and van Donkelaar et al. (2019) $\mathrm{PM}_{2.5}$ estimates from 2015 versus GEOS-Chem $\mathrm{PM}_{2.5}$ estimates (panel b). GEOS-Chem PM PM. $_{2.5}$ estimates are from the bulk-aerosol model configuration under the continued-residential-coal-use scenario (base case). $\mathrm{PM}_{2.5}$ surface measurements were collected by the China National Environmental Monitoring Center (CNEMC; http://www.cnemc.cn/) and the Beijing Municipal Environmental Monitoring Center (BMEMC, http://www.bjmemc.com.cn/). Data are compared as annual averages. The measurements or van Donkelaar et al. (2019) estimates were compared to the model using the slope, coefficient of determination $\left(\mathrm{R}^{2}\right)$, mean bias $(\mathrm{MB})$, mean error $(\mathrm{ME})$, mean normalized bias $(\mathrm{MNB})$, mean normalized error (MNE), and normalized mean bias factor (NMB). MNB, MNE, and NMB are normalized by the observations and are expressed as percentages, while MB and ME are not normalized and are expressed in units of $\mu \mathrm{g} \mathrm{m}^{-3}$. The solid line on each plot shows a 1:1 relationship between the measurements and the model, while the dashed line shows the line of best fit (equation given on each figure). 
Donkelaar et al. (2019) (which combine models, satellite data, and in situ measurements) (Figs. 1 and 2). The GEOSChem bulk-aerosol model may be biased because emissions controls have been implemented in China across other sectors (e.g., power, industrial, transportation) since 2010, meaning that the MIX 2010 emissions inventory may overestimate the actual emissions. (See Zheng et al. (2018) for a summary of China's clean air policies and their effect on emissions.) Additionally, nitrate is biased high in the GEOS-Chem model compared to measurements. This matter is discussed elsewhere (Heald et al., 2012). The $\mathrm{PM}_{2.5}$ measurements from the TEOM and BAM monitors are also subject to bias. For example, both the TEOM and BAM are typically heated, thus semi-volatile $\mathrm{PM}_{2.5}$ may evaporate, causing $\mathrm{PM}_{2.5}$ mass measurements to be biased low (Chung et al., 2001). We acknowledge that known biases in $\mathrm{PM}_{2.5}$ measurements and modeled output contribute to uncertainty in our mortality estimates. Overall, the high $\mathrm{PM}_{2.5}$ baseline estimates from the model may lead our Subtraction-Method health-effect estimates to be negatively biased, given the non-linear nature of the IER function. Additionally, both the Subtraction-Method and Attribution-Method estimates may be underestimated if residential coal represents a larger fraction of total ambient $\mathrm{PM}_{2.5}$ than our estimates, because of China's clean air policies that have impacted other emissions sectors. However, we expect these uncertainties to be similar to other studies and smaller than the uncertainties due to other inputs to the mortality calculation, such as uncertainties in concentrationresponse functions and baseline mortality rates (Ford and Heald, 2016; Kodros et al., 2018).

\section{Estimated Changes in $P_{2.5}$ under the Residential Coal Ban}

For the Beijing-off scenario, $\mathrm{PM}_{2.5}$ was reduced a maximum of $14.9 \%$ within Beijing (domain-average reduction: $0.2 \%$ ), while for the Beijing-Tianjin-Hebei-off simulation, $\mathrm{PM}_{2.5}$ was reduced a maximum of $26.3 \%$ near the border of Beijing and Hebei (domain-average reduction: 2.4\%) (Fig. 1). $\mathrm{PM}_{2.5}$ reductions are a result of emission changes in both primary aerosols (e.g., $\mathrm{BC}, \mathrm{OC}, \mathrm{SO}_{4}$ ) and aerosol precursor vapors (e.g., $\mathrm{SO}_{2}, \mathrm{NO}$, secondary organic aerosol precursors).
Under both coal-ban scenarios, the largest reductions in $\mathrm{PM}_{2.5}$ due to the simulated coal bans were predicted to be in the residential-coal-ban region. The estimated reductions in $\mathrm{PM}_{2.5}$ due to the coal-ban scenarios decayed quickly downwind of the residential-coal-ban region, especially in the Beijingonly scenario, because several of the provinces surrounding Beijing-Tianjin-Hebei have high primary emissions (Fig. S10); thus, transported air pollution from Beijing-Tianjin-Hebei has a small relative influence on $\mathrm{PM}_{2.5}$ in these surrounding provinces.

We found a maximum reduction of $26.3 \%$ in winteraveraged $\mathrm{PM}_{2.5}$ in the Beijing-off case and $44.4 \%$ in the Beijing-Tianjin-Hebei-off case. These estimates are similar to Liu et al. (2016) (who estimated that a similar Beijing-off scenario would reduce the winter-average surface $\mathrm{PM}_{2.5}$ in Beijing by $22 \pm 6 \%$ and a similar Beijing-Tianjin-Hebei-off scenario would reduce $\mathrm{PM}_{2.5}$ concentrations in Beijing by 40 $\pm 9 \%$ ) and Zhang et al. (2017) (who estimated that residential coal contributed to $46 \%$ of the winter-average $\mathrm{PM}_{2.5}$ in Beijing-Tianjin-Hebei).

\section{Estimated PM 2.5 -related Health Effects of the Residential Coal Ban}

Using the Subtraction Method (described above in "Health effects" section), we estimate that within China, the Beijing-off scenario could lead to 1,900 deaths averted per year (95\% confidence interval (CI): 1,200-2,700 deaths per year), while the Beijing-Tianjin-Hebei-off scenario could lead to 13,700 deaths averted per year (95\% CI: 8,90019,600 deaths per year) (Fig. 3). The majority of these deaths are from cardiovascular disease (Beijing-off: 57\%; BeijingTianjin-Hebei-off: 58\%). (Deaths averted per capita and by cause of death and simulation year are shown in Figs. S12 and $\mathrm{S} 13$, respectively.)

In China, the population-weighted $\mathrm{PM}_{2.5}$ levels in the simulation domain change from $47.7 \mu \mathrm{g} \mathrm{m}^{-3}$ (IQR: 21.7$78.4 \mu_{\mathrm{g} \mathrm{m}^{-3}}$ ) in the continued-residential-coal-use (base-

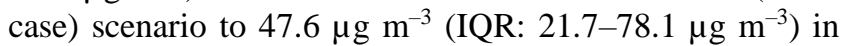
the Beijing-off and $46.3 \mu \mathrm{g} \mathrm{m}^{-3}$ (IQR: $27.1-75.0 \mu \mathrm{g} \mathrm{m}^{-3}$ ) in the Beijing-Tianjin-Hebei-off scenario. These $\mathrm{PM}_{2.5}$ levels fall on the flatter part of IER function; thus, the reduction in
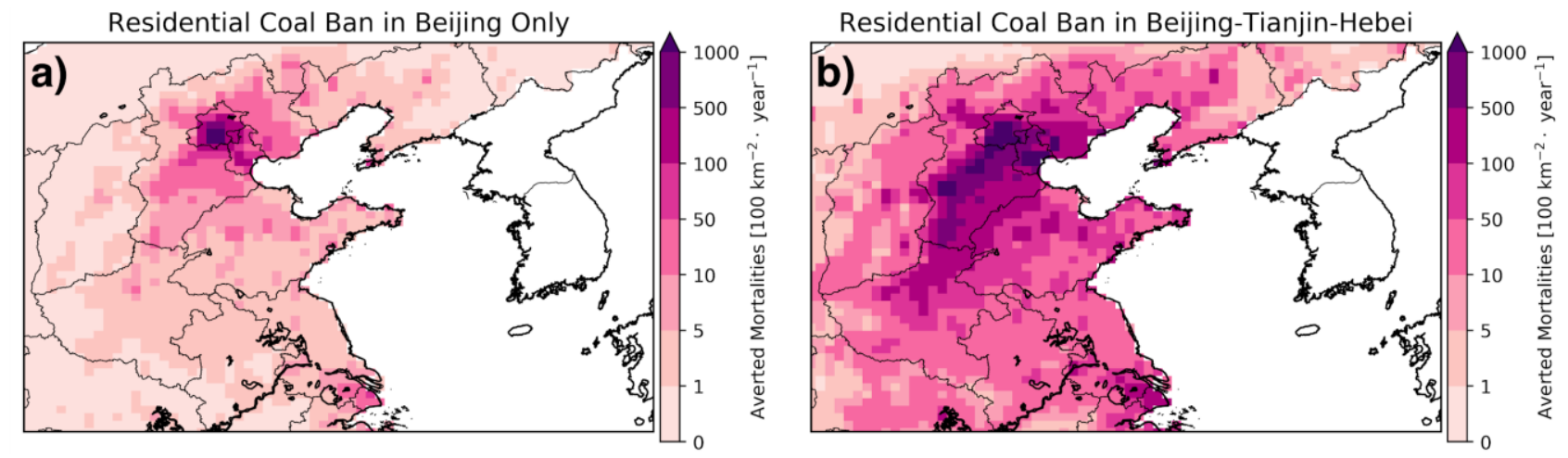

Fig. 3. Estimated fine particulate matter $\left(\mathrm{PM}_{2.5}\right)$-related mortalities averted (per area) under the coal-ban scenarios (Beijingoff in panel a and Beijing-Tianjin-Hebei-off in panel b) using the Subtraction Method. Results are an average of two consecutive simulation years (December 2014-November 2015 and December 2015-November 2016). Annual averted mortalities are calculated in China only using the GEOS-Chem bulk-aerosol model configuration. 
relative risk of cardiovascular mortality at these $\mathrm{PM}_{2.5}$ levels will be lower than what could be achieved with same $\mathrm{PM}_{2.5}$ reductions in a setting that has lower $\mathrm{PM}_{2.5}$ levels to begin with (Burnett et al., 2014). If the annual ambient $\mathrm{PM}_{2.5}$ levels were reduced to levels where the IER function has a steeper slope, there may be a considerable increase in the number of mortalities that could be averted from $\mathrm{PM}_{2.5}$. Emissions controls across other sectors, as part of China's Clean Air Action Plan (Zheng et al., 2018), which are not captured here, may increase our estimates of $\mathrm{PM}_{2.5}$-related deaths averted from the residential coal ban. (See the "Modelled and Measured $\mathrm{PM}_{2.5}$ " section for further discussion.)

Using the Attribution Method (described above in the "Health effects" section), we estimate that 6,400 deaths per year (95\% CI: 4,200-8,000 mortalities per year) are attributable to $\mathrm{PM}_{2.5}$ emissions from residential coal in Beijing and 44,900 deaths per year (95\% CI: 29,900-56,500 deaths per year) are attributable to residential coal in Beijing-TianjinHebei. (Deaths per area are in Figure S14 and deaths per capita are in Fig. S15.) These estimates are about three times greater than the number of premature deaths that would be averted from eliminating residential coal (Subtraction Method, above) because the Attribution Method is not affected by the non-linear exposure-response functions (e.g. a $50 \%$ reduction in $\mathrm{PM}_{2.5}$ leads to a $50 \%$ reduction in $\mathrm{PM}_{2.5}$-attributable mortality, regardless of baseline air pollution level). Our Attribution-Method estimates compare well with previous Attribution-Method estimates from Archer-Nicholls et al. (2016), who estimated that the residential sector (including both biomass and coal) contributes to an estimated 32,152 yearly premature deaths in the Beijing-Tianjin-Hebei region (Beijing: 5,017 (95\% CI: 4,391-5,677) yearly deaths; Tianjin: 3,401 (95\% CI: 2,852-4,001); Hebei: 23,734 (95\% CI: 20,535-26,614)). These estimates are smaller than ours because our calculations also include deaths attributed to
$\mathrm{PM}_{2.5}$ from residential coal use in the Beijing-Tianjin-Hebei region that is transported to surrounding provinces.

\section{Aerosol Climate Effects of the Residential Coal Ban \\ Modelled and Measured Aerosol Mass and Composition}

In the Base-case scenario, the average mass of $\mathrm{BC}$ in the atmospheric column across the simulation domain was 2.86 $\mathrm{mg} \mathrm{m}^{-2}$ (IQR: $1.42-4.16 \mathrm{mg} \mathrm{m}^{-2}$ ), the average mass of OA + $\mathrm{SO}_{4}$ in the column was $46.1 \mathrm{mg} \mathrm{m}^{-2}$ (IQR: 26.7-63.5 $\mathrm{mg} \mathrm{m}^{-2}$ ) (Fig. 4; Fig. S16 shows OA and $\mathrm{SO}_{4}$ separately). Both BC and $\mathrm{OA}+\mathrm{SO}_{4}$ followed trends similar to that of surface $\mathrm{PM}_{2.5}$ (Fig. 1). The changes between the base-BC/OA case and the high-BC/low-OA case and low-BC/high-OA are shown in Figs. S17 and S18, respectively. The high-BC/low-OA case substantially increased $\mathrm{BC}$ loading in the atmospheric column, while decreasing OA loading; the inverse was true for the low-BC/high-OA case.

AOD measurements can be used to indirectly validate the total mass of aerosol in the column (Fig. S17). We find that the model captures $74.9 \%$ of the measured variability in AOD and only slightly underpredict the AERONET AOD measurements (NMB: $-4.4 \%$ ).

Number concentrations of particles with diameter larger than $10 \mathrm{~nm}$ (N10) and $80 \mathrm{~nm}$ (N80) are shown in Fig. 5. N10 is an indicator of total particle number and is measured by many particle counters (e.g., condensation particle counter (CPC)), while N80 is a proxy for cloud-condensation nuclei (CCN). In the Base-case scenario, at the low-cloud level ( $900 \mathrm{hPa})$, the average N10 concentration across the simulation domain is $7,000 \mathrm{~cm}^{-3}$ (IQR: $5,000-8,900 \mathrm{~cm}^{-3}$ ) and the average N80 concentration is $4,100 \mathrm{~cm}^{-3}$ (IQR: $2,300-5,600 \mathrm{~cm}^{-3}$ ) (Fig. 5). Higher concentrations of N10 and N80 appeared near sources (Fig. S10). Primary particles from residential combustion are assumed to be emitted in the Aitken mode (centered at $30 \mathrm{~nm}$ ) in the model.

SSA is a function of both the composition and number of
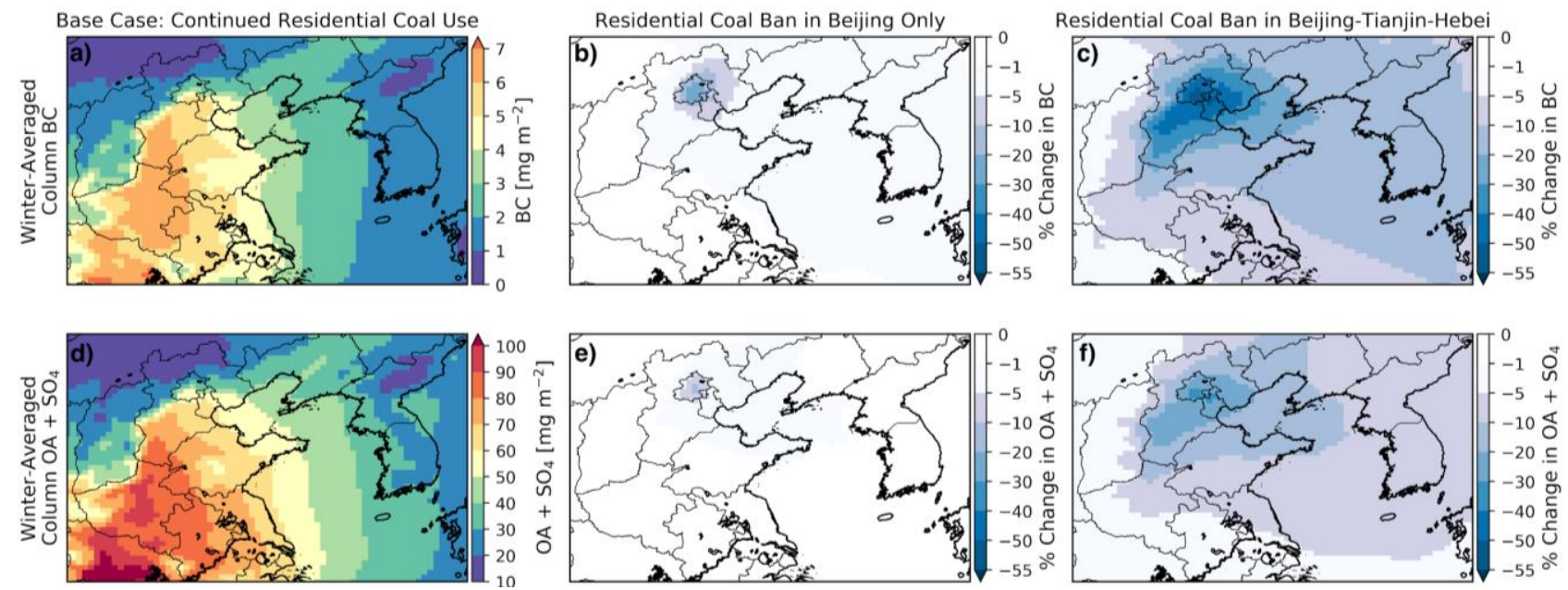

Fig. 4. Total mass of black carbon (BC) (panels a, b, and c) and organic aerosol + sulfate $\left(\mathrm{OA}+\mathrm{SO}_{4}\right)($ panels d, e, and f) in the atmospheric column (using the GEOS-Chem-TOMAS model configuration). The base case simulation (continued residential coal use) is given as an absolute mass concentration (panels a and d), while the coal-ban simulations are given as a percentage-change relative to the base case (Beijing-off in panels $b$ and e and Beijing-Tianjin-Hebei-off in panels $c$ and $f$ ). Results are an average of two winters (December 2014 through February 2015 and December 2015 through February 2016). 

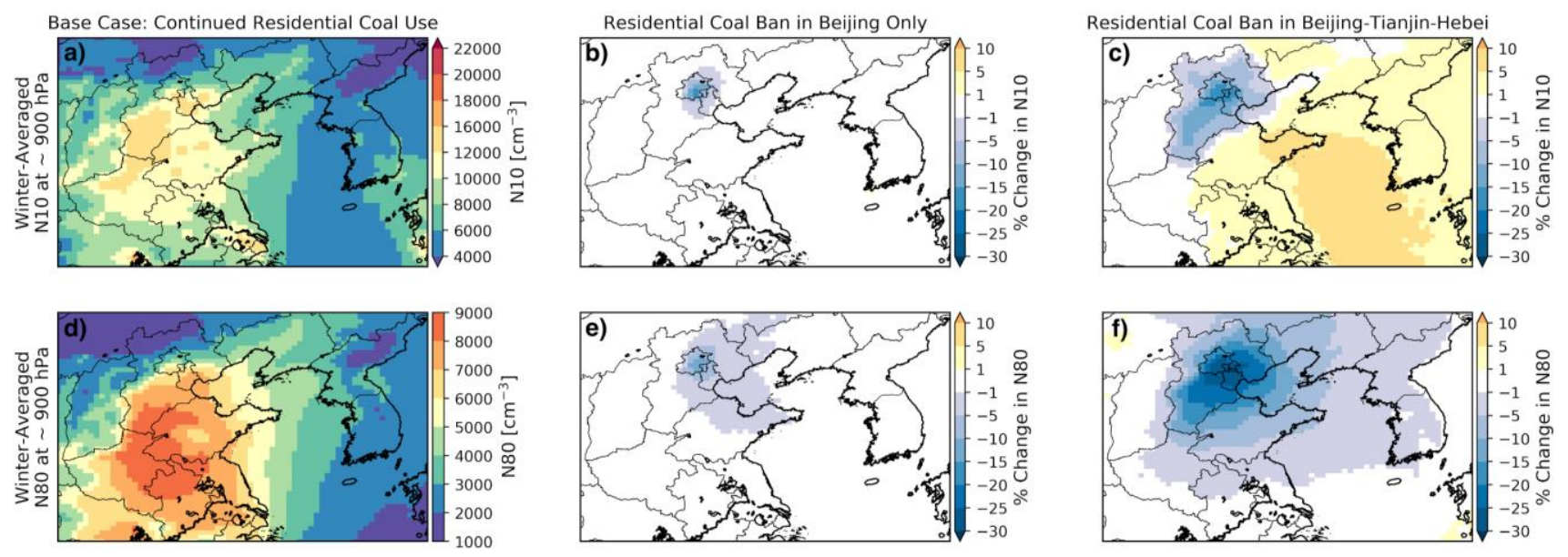

Fig. 5. Total number of particles with diameters greater than $10 \mathrm{~nm}$ (N10) (panels a, b, and c) and diameters greater than $80 \mathrm{~nm}$ (N80) (panels d, e, and f) at $\sim 900 \mathrm{hPa}$ from the GEOS-Chem-TOMAS model configuration. The base case simulation (continued residential coal use) is given as an absolute number concentration (panels a and d), while the coal-ban simulations are given as percentage changes relative to the base case (Beijing-off in panels $b$ and e and Beijing-Tianjin-Hebei-off in panels c and f). Results are an average of two winters (December 2014 through February 2015 and December 2015 through February 2016).

particles in the atmospheric column. Fig. 6 shows 2D histograms comparing SSA measurements from AERONET to SSA estimates from GEOS-Chem-TOMAS under the base-BC/OA case across four mixing-state assumptions (i.e., external, core-shell, Maxwell-Garnett, and volume). SSA from the model was negatively biased (NMB range: -3.0 to $-8.1 \%)$; however, across the base-BC:OA cases, the external mixing-state assumption (NMB: $-3.0 \%$ ) had the lowest bias. Similar comparisons using the high-BC/low-OA case and the low-BC/high-OA case are in Figs. S20 and Fig. S21, respectively. Across all comparisons, the SSA from the model was negatively biased (NMB range: $-2.1 \%$ to $-11.3 \%$ ) and, overall, the external mixing state assumption under the lowBC/high-OA case had the smallest bias (NMB: $-2.1 \%$ ). This conclusion suggests that the external mixing state, with no absorption enhancement for BC, may be most appropriate for this region; however, we do not independently compare the modelled aerosol composition to measurements, so it is possible that the predicted BC fraction is too high.

\section{Estimated Changes in Aerosol Mass and Number under the Residential Coal Ban}

Both $\mathrm{BC}$ and $\mathrm{OA}+\mathrm{SO}_{4}$ are reduced substantially under the two coal-ban scenarios (Fig. 4; Fig. S16 shows OA and $\mathrm{SO}_{4}$ reductions separately). For the Beijing-off scenario, BC was reduced a maximum of $28.0 \%$, and $\mathrm{OA}+\mathrm{SO}_{4}$ was reduced a maximum of $10.2 \%$ across the simulation domain. For the Beijing-Tianjin-Hebei-off scenario, $\mathrm{BC}$ was reduced a maximum of $53.6 \%$, and $\mathrm{OA}+\mathrm{SO}_{4}$ was reduced a maximum of $32.4 \%$ across the simulation domain. The largest reductions were concentrated in Beijing, Tianjin, and Hebei under both coal-ban scenarios, while reductions were smaller outside of Beijing-Tianjin-Hebei with a pattern similar to surface $\mathrm{PM}_{2.5}$ (Fig. 1).

N10 decreased under both coal-ban scenarios in the provinces of Beijing, Tianjin, and Hebei; however, N10 increased on average across the domain in both coal-ban scenarios (Fig. 5). For the Beijing-off scenario, N10 was reduced a maximum of $15.6 \%$ with a maximum increase of $1.1 \%$. For the Beijing-Tianjin-Hebei scenario, N10 was reduced a maximum of $18.9 \%$ with a maximum increase of $7.8 \%$. The increase in N10 concentration between the basecase and coal-ban scenarios indicates that particle nucleation rates may increase when residential coal emissions are reduced. Similar nucleation feedbacks have been seen when other primary emissions sources are reduced (Westervelt $e t$ al., 2014; Kodros et al., 2015, 2016b). In contrast to N10, $\mathrm{N} 80$ (which is a proxy for $\mathrm{CCN}$ ) decreased substantially across the simulation domain in both coal-ban scenarios (Fig. 5), indicating that zeroing out primary emissions from residential coal has a greater impact on N80 than the change in nucleation rates that impacted N10. For the Beijing-off scenario, $\mathrm{N} 80$ was reduced a maximum of $13.5 \%$, while for the Beijing-Tianjin-Hebei-off scenario, N80 was reduced a maximum of $30.4 \%$.

\section{Estimated Aerosol Direct Effect of the Residential Coal Ban}

Across all sensitivity cases, for both residential-coal-ban scenarios, removing the residential source led to a positive domain-average DRE, because overall the aerosol from residential combustion had a cooling effect (Beijing-off maps are shown in Fig. S22, Beijing-Tianjin-Hebei-off maps are shown in Fig. 7, and domain-level statistics for both winters are shown in Fig. 8). Following the changes in aerosol mass and number shown in Figs. 5 and 6, the DRE effects in the Beijing-Tianjin-Hebei-off scenario were substantially larger than the Beijing-off scenario. For example, under the external mixing-state assumption and the base-BC/OA case, the DRE in the Beijing-off residential-coal-ban scenario was $0.023 \mathrm{~W} \mathrm{~m}^{-2}$, while the Beijing-Tianjin-Hebei-off scenario was $0.30 \mathrm{~W} \mathrm{~m}^{-2}$. 

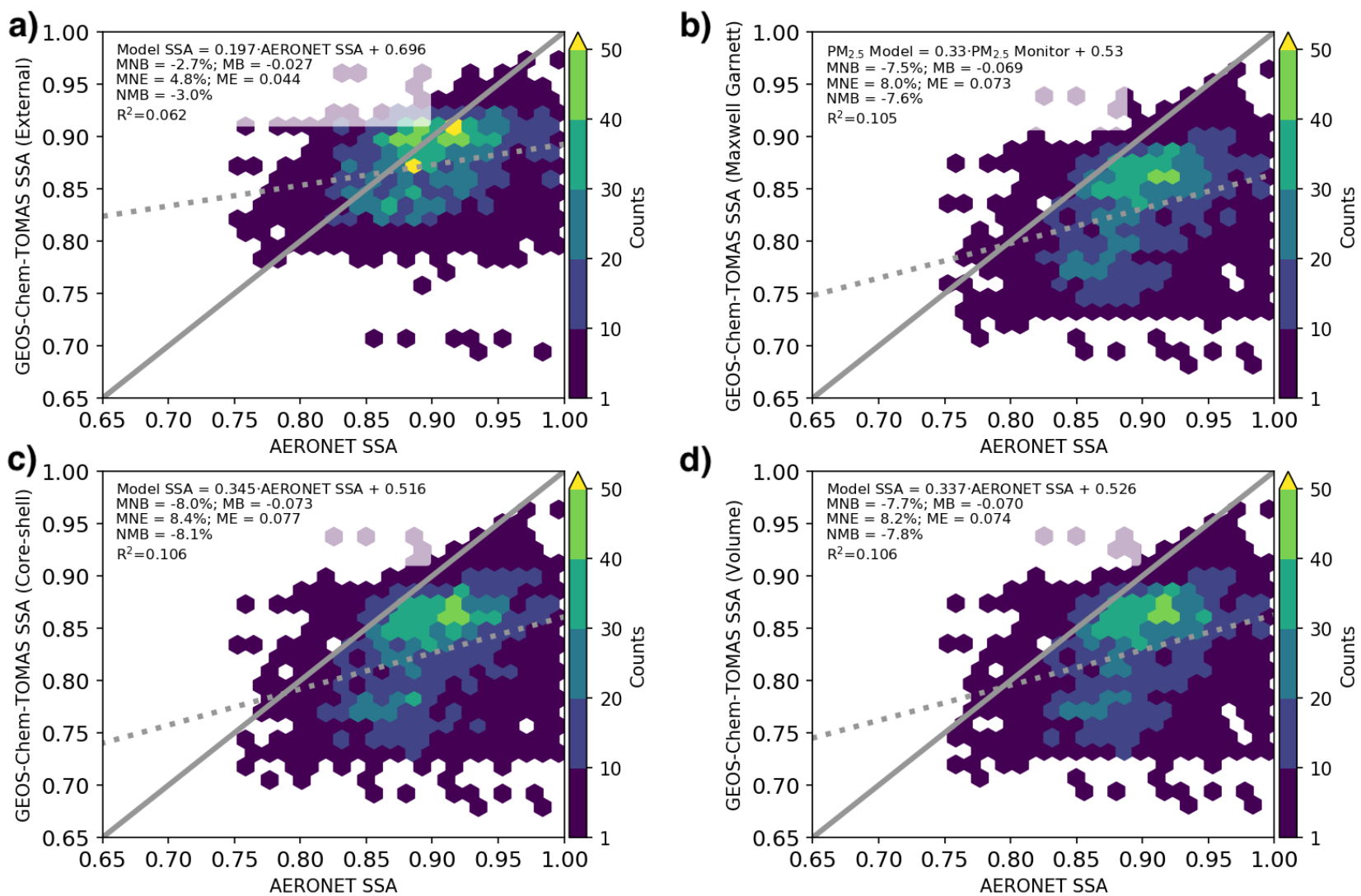

Fig. 6. Single scattering albedo (SSA) measurements from AERONET versus GEOS-Chem-TOMAS SSA under four mixing-state assumptions (i.e., external (panel a), Maxwell-Garnett (panel b), core-shell (panel c), and volume (panel d)) at $440 \mathrm{~nm}$. The GEOS-Chem-TOMAS model output is from the base case scenario (continued residential coal use) under the base-BC/OA case. The measurements were compared to the model using the slope, coefficient of determination $\left(\mathrm{R}^{2}\right)$, mean bias (MB), mean error (ME), mean normalized bias (MNB), mean normalized error (MNE), and normalized mean bias factor (NMB). MNB, MNE, and NMB are normalized by the observations and are expressed as percentages, while MB and ME are not normalized and are expressed in units of $\mu \mathrm{g} \mathrm{m}^{-3}$. The solid line on each plot shows a 1:1 relationship between the measurements and the model, while the dashed line shows the line of best fit (equation given on each figure).

The mixing-state assumption influenced the estimated DRE substantially. Overall, the estimated radiative forcing due to the coal bans decreased (became less positive) as the aerosol mixing state became more internally mixed. For example, under the Beijing-Tianjin-Hebei-off scenario and the base-BC/OA case, the average DRE across the domain was $0.30 \mathrm{~W} \mathrm{~m}^{-2}$ for external, $0.25 \mathrm{~W} \mathrm{~m}^{-2}$ for Maxwell-Garnett, $0.24 \mathrm{~W} \mathrm{~m}^{-2}$ for core-shell, and $0.23 \mathrm{~W} \mathrm{~m}^{-2}$ for volume mixing state assumptions. Under the external mixing state assumption, the absorption of $\mathrm{BC}$ is not enhanced as it is when the internal mixing state assumptions are applied. Thus, removing particles that are more externally mixed contributes to a larger positive radiative forcing compared to the removal of more internally mixed particles (i.e., Maxwell Garnett, core-shell, or volume). The SSA comparison shown in Fig. 6 indicates that the external-mixing assumption, which leads to the highest radiative-forcing estimates for the coal bans, agreed best with the observed SSA, and hence may be the most representative assumption of aerosols in the region.

The assumed $\mathrm{BC}: \mathrm{OA}$ ratio of residential coal emissions also influenced the DRE, with higher $\mathrm{BC}$ :OA ratios leading to smaller positive radiative forcings from removing residential coal. For example, for under the Beijing-Tianjin-Hebei-off and external mixing state assumption, the domain-average DRE for the high-BC/low-OA case was $0.23 \mathrm{~W} \mathrm{~m}^{-2}$, the base-BC/OA case was $0.30 \mathrm{~W} \mathrm{~m}^{-2}$, and the low-BC/high$\mathrm{OA}$ case was $0.33 \mathrm{~W} \mathrm{~m}^{-2}$. Note that, along with $\mathrm{BC}$ and $\mathrm{OA}$ emissions, $\mathrm{SO}_{2}$ emissions from residential coal were turned off in the ban scenarios, which means that sulfate is also reduced downwind of the ban regions. Reductions in sulfate contribute to the warming tendency of the ban $\left(\mathrm{SO}_{4}\right.$ was reduced a maximum of $3.0 \%$ in the Beijing-off scenario and $8.1 \%$ in the Beijing-Tianjin-Hebei-off scenario). In some instances, the ban scenarios in the high-BC/low-OA cases led to a localized cooling within the model domain over regions with brighter surfaces (Fig. S23). For example, under the high-BC/low-OA case when the aerosol particles were internally mixed (i.e., Maxwell Garnett, core-shell, or volume) there was a negative radiative forcing to the south of Beijing (Figs. S22 and 7). However, we have confidence that the residential coal ban will have a climate warming tendency, because across all sensitivity cases, for both residential-coal-ban scenarios, removing residential-coal 

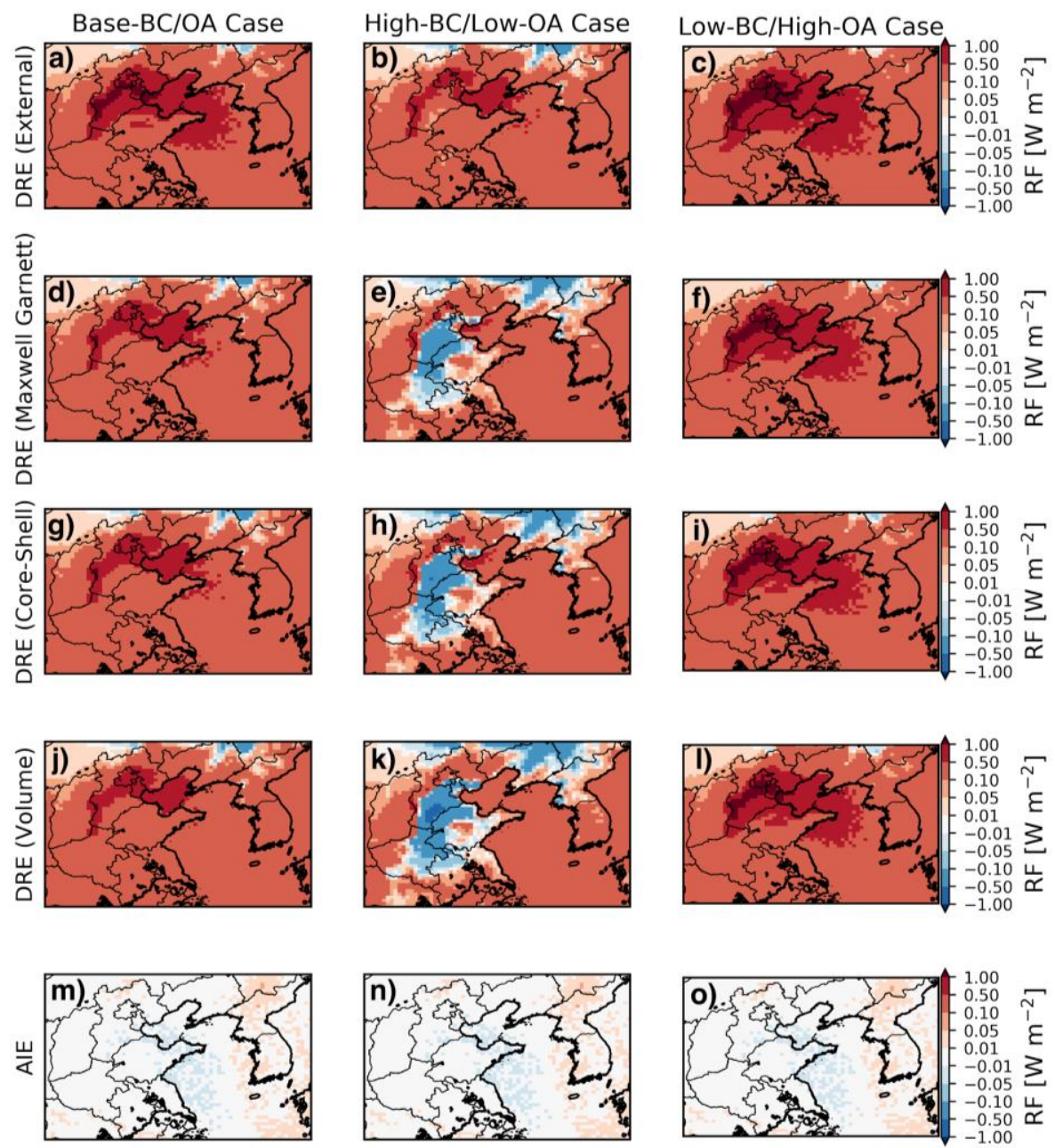

Fig. 7. Estimated aerosol direct radiative effect (DRE) and cloud-albedo indirect effect (AIE) under the Beijing-TianjinHebei-off scenario. DRE estimates are calculated under four different black carbon (BC) mixing-state assumptions (i.e., external (panels a, b, and c), Maxwell Garnett (panels d, e, and f), core-shell (panels g, h, and i), and internal (panels j, k, and 1)). Both DRE and AIE estimates are calculated under three different BC emissions sensitivity cases (i.e., the base$\mathrm{BC} / \mathrm{OA}$ case (panels a, d, g, j, m), the high-BC/low-OA case (panels b, e, h, k, n), and the low-BC/high-OA case (panels c, $\mathrm{f}, \mathrm{i}, \mathrm{l}, \mathrm{o})$ ). Results are using the GEOS-Chem-TOMAS configuration and are an average of two winters (December 2014 through February 2015 and December 2015 through February 2016).

emissions led to a positive domain-average DRE. Additionally, the sensitivity case that had the lowest bias when compared to SSA measurements (the low-BC/high-OA case with externalmixing assumption) had the largest positive radiativeforcing estimate under both ban scenarios.

A previous study by Archer-Nicholls et al. (2019), which used the Maxwell-Garnett mixing-state assumption (i.e., BC spheres are randomly distributed within the homogenous particle composed of the more-scattering aerosol components), estimated that emissions from residential coal have a positive DRE $\left(0.79 \mathrm{~W} \mathrm{~m}^{-2}\right.$ and ranging from 1.38 to $-0.01 \mathrm{~W} \mathrm{~m}^{-2}$ over Eastern China, due changing the BC:OA ratio), which would lead to a negative DRE from removing these emissions, the opposite of what we estimate. The estimate reported by Archer-Nicholls et al. (2019) is larger in magnitude, likely because they excluded residential combustion (i.e., both biomass and coal use) across all of China, rather than just in Beijing or Beijing-Tianjin-Hebei. The difference in sign could be due to differences in aerosol absorption. ArcherNicholls et al. (2019) tested their aerosol properties as we did against AERONET. Based on SSA comparisons, they found that the aerosol in their model was more absorbing than observed for their high-BC and base emissions cases, while the SSA from their low-BC emissions case, which resulted in the same sign as our estimate, was closer to AERONET observations. Our results agreed that the internal mixing-state assumptions may lead to excess absorption. Additionally, our results agree that the low-BC/high-OA case (which assumes that residential-coal emissions are more scattering than the high-BC/low-OA and base-BC/OA case) may be the most representative of aerosol composition in our model region.

\section{Cloud-albedo Aerosol Indirect Effect of the Residential Coal Ban}

Under all sensitivity cases, the residential-coal-ban 

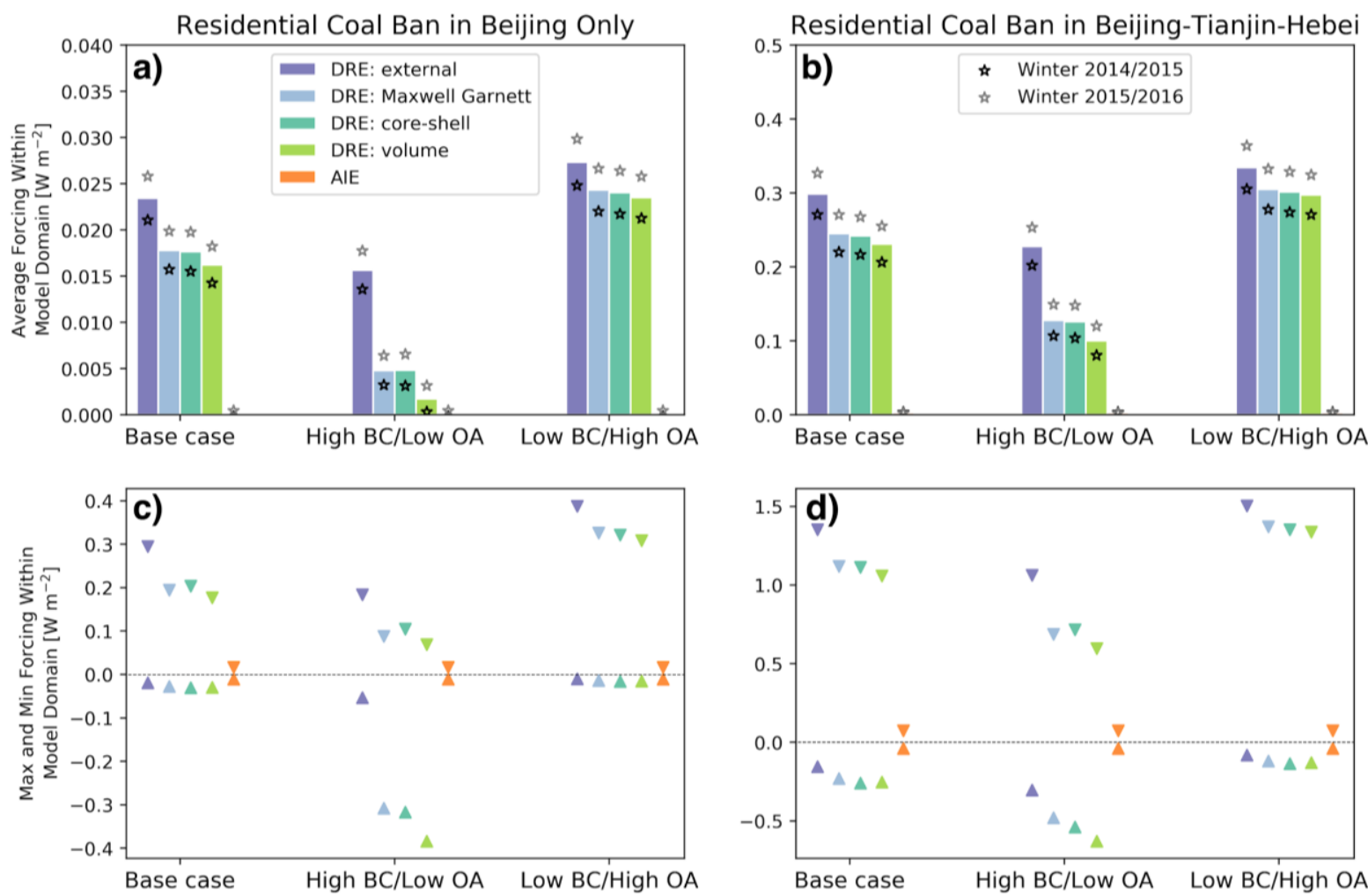

Fig. 8. Estimated aerosol direct radiative effect (DRE) and cloud-albedo indirect effect (AIE) from the Beijing-off (panel a and c) and Beijing-Tianjin-Hebei-off (panel b and d) coal-ban cases. DRE estimates are calculated under four different black carbon (BC) mixing-state assumptions (i.e., external, Maxwell Garnett, core-shell, and internal). Both DRE and AIE estimates are calculated under three different BC/OA emissions cases (i.e., base-BC/OA case, high-BC/low-OA case, and low-BC/high-OA case). The average, minimum, and maximum across the simulation domain from two simulated winters (December 2014 through February 2015 and December 2015 through February 2016) are shown in panels a and b, the bars indicate the average across both winters and the markers indicate the domain-average radiative forcing from each of the two simulated winters. In panels $\mathrm{c}$ and d, max and min forcings are from the two-year domain average. Results were calculated using the GEOS-Chem-TOMAS simulations.

scenarios are estimated to lead to a small positive average cloud-albedo AIE across the simulation domain because the number of CCN (i.e., N80) was reduced. The AIE increased in the west of the simulation domain, over North and South Korea, and decreased to the southeast of Beijing, over the ocean. The predicted cloud-albedo AIE is several orders of magnitude smaller than the DRE. For example, under the base-BC/OA case, the cloud-albedo AIE for the Beijing-off residential-coal-ban scenario was $0.0001 \mathrm{~W} \mathrm{~m}^{-2}$, while the Beijing-Tianjin-Hebei-off scenario was $0.0027 \mathrm{~W} \mathrm{~m} \mathrm{~m}^{-2}$ (compared to 0.023 and $0.30 \mathrm{~W} \mathrm{~m}^{-2}$ for DRE for the two scenarios, respectively). Overall, the activation of $\mathrm{CCN}$ is less sensitive to aerosol particle composition than the aerosol optical properties in the DRE calculation. The sign of the radiative forcing from the cloud-albedo AIE estimated by (Archer-Nicholls et al., 2019) agreed with our AIE estimates; however, their estimate was larger in magnitude, since they estimated the radiative forcing of residential combustion (i.e., both biomass and coal use) across all of China.

\section{CONCLUSIONS}

In this work, we used the GEOS-Chem chemical- transport model to estimate the health and radiative effects of the residential coal-to-electricity policy that is currently being implemented in Beijing-Tianjin-Hebei. Assuming a complete coal-to-electricity transition in the residential sector, we estimate that a substantial number of premature deaths could be averted per year from a residential coal ban in the Beijing province alone (1,900 deaths averted annually (95\% CI: $1,200-2,700)$ ) or a residential coal ban in the greater Beijing-Tianjin-Hebei region (13,700 deaths averted annually (95\% CI: 8,900-19,600)). When considering only the aerosol-related effects, we do not anticipate that any estimated health benefits of the residential-coal transition will be coupled with climate "co-benefits". Instead, we estimate that removing residential coal emissions will lead to a positive DRE (average external DRE with base-BC/OA case across the model domain Beijing-off: $0.023 \mathrm{~W} \mathrm{~m}^{-2}$; Beijing-Tianjin-Hebei-off: $0.30 \mathrm{~W} \mathrm{~m}^{-2}$ ) and cloud-albedo AIE (average AIE with base-BC/OA case across the model domain Beijing-off: $0.0001 \mathrm{~W} \mathrm{~m}^{-2}$; Beijing-Tianjin-Hebeioff: $0.0027 \mathrm{~W} \mathrm{~m}^{-2}$ ). However, we note that our radiative forcing estimates do not take into account how greenhouse gas emissions (i.e., $\mathrm{CO}_{2}, \mathrm{CH}_{4}$ ) will change or how increased energy demand will affect aerosols under the coal-to- 
electricity policies. (According to the MIX v2010 inventory, residential contributes $12 \%$ of the $\mathrm{CO}_{2}$ emissions in BeijingTianjin-Hebei.) Overall, if the coal-to-electricity policy is coupled with a net reduction in greenhouse gas emissions (i.e., if there is less net greenhouse gas emissions due to the replacement heaters) and maintains similar aerosol reductions (since centralized electricity generation will likely have lower emissions than residential coal), the policy may be able to achieve health and climate "co-benefits".

\section{ACKNOWLEDGEMENTS}

We acknowledge the Monfort Excellence Fund and the National Natural Science Foundation of China (Grant \#: 41830641) for their support of this research.

\section{SUPPLEMENTARY MATERIAL}

Supplementary data associated with this article can be found in the online version at https://doi.org/10.4209/aaqr.2 019.11 .0565

\section{REFERENCES}

Adams, P.J. and Seinfeld, J.H. (2002). Predicting global aerosol size distributions in general circulation models. $J$. Geophys. Res. 107: 4370. https://doi.org/10.1029/2001JD 001010

Archer-Nicholls, S., Carter, E., Kumar, R., Xiao, Q., Liu, Y., Frostad, J., Forouzanfar, M. H., Cohen, A., Brauer, M., Baumgartner, J. and Wiedinmyer, C. (2016). The regional impacts of cooking and heating emissions on ambient air quality and disease burden in China. Environ. Sci. Technol. 50: 9416-9423. https://doi.org/10.1021/acs.est.6 b02533

Archer-Nicholls, S., Lowe, D., Lacey, F., Kumar, R., Xiao, Q., Liu, Y., Carter, E., Baumgartner, J. and Wiedinmyer, C. (2019). Radiative effects of residential sector emissions in China: Sensitivity to uncertainty in black carbon emissions. J. Geophys. Res. 124: 5029-5044. https://doi.org/10.1029/ 2018JD030120

Barrington-Leigh, C., Baumgartner, J., Carter, E., Robinson, B. E., Tao, S. and Zhang, Y. (2019). An evaluation of air quality, home heating and well-being under Beijing's programme to eliminate household coal use. Nat. Energy 4: 416-423. https://doi.org/10.1038/s41560-019-0386-2

Berman, L. (2017). National AQI observations (2014-05 to 2016-12), Harvard Dataverse. https://doi.org/10.7910/DV N/QDX6L8

Bohren, C.F. and Huffman, D.R. (1983). Absorption and scattering of light by small particles, Wiley Interscience, New York, USA.

Bond, T.C., Habib, G. and Bergstrom, R.W. (2026). Limitations in the enhancement of visible light absorption due to mixing state. J. Geophys. Res. 111: D20211. https://doi.org/10.1029/2006JD007315

Burnett, R.T., Pope, C.A., Ezzati, M., Olives, C., Lim, S.S., Mehta, S., Shin, H.H., Singh, G., Hubbell, B., Brauer, M., Anderson, H.R., Smith, K.R., Balmes, J.R., Bruce, N.G.,
Kan, H., Laden, F., Prüss-Ustün, A., Turner, M.C., Gapstur, S.M., Diver, W.R. and Cohen, A. (2014). An integrated risk function for estimating the global burden of disease attributable to ambient fine particulate matter exposure. Environ. Health Perspect. 122: 397-403. https://doi.org/10.1289/ehp.1307049

Cappa, C.D., Onasch, T.B., Massoli, P., Worsnop, D.R., Bates, T.S., Cross, E.S., Davidovits, P., Hakala, J., Hayden, K.L., Jobson, B.T., Kolesar, K.R., Lack, D.A., Lerner, B.M., Li, S.M., Mellon, D., Nuaaman, I., Olfert, J.S., Petaja, T., Quinn, P.K., Song, C., Subramanian, R., Williams, E.J. and Zaveri, R.A. (2012). Radiative absorption enhancements due to the mixing state of atmospheric black carbon. Science 337: 1078-1081. https://doi.org/10. 1126/science. 1223447

Chan, C.K. and Yao, X. (2008). Air pollution in mega cities in China. Atmos. Environ. 42: 1-42. https://doi.org/10.10 16/j.atmosenv.2007.09.003

Chung, A., Chang, D.P.Y., Kleeman, M.J., Perry, K.D., Cahill, T.A., Dutcher, D., McDougall, E.M. and Stroud, K. (2001). Comparison of real-time instruments used to monitor airborne particulate matter. J. Air Waste Manage. Assoc. 51: 109-120. https://doi.org/10.1080/10473289.20 01.10464254

David, L.M., Ravishankara, A.R., Kodros, J.K., Pierce, J.R., Venkataraman, C. and Sadavarte, P. (2019). Premature mortality due to $\mathrm{PM}_{2.5}$ over India: Effect of atmospheric transport and anthropogenic emissions. GeoHealth 3: 210. https://doi.org/10.1029/2018GH000169

Ford, B. and Heald, C.L. (2016). Exploring the uncertainty associated with satellite-based estimates of premature mortality due to exposure to fine particulate matter. Atmos. Chem. Phys. 16: 3499-3523. https://doi.org/10.51 94/acp-16-3499-2016

Garnett, J.C.M. (1904). Colours in metal glasses and in metallic films. Philos. Trans. R. Soc. London, Ser. A 203: 385-420.

Heald, C.L., Collett, J.L., Lee, T., Benedict, K.B., Schwandner, F.M., Li, Y., Clarisse, L., Hurtmans, D.R., Van Damme, M., Clerbaux, C., Coheur, P.F., Philip, S., Martin, R.V. and Pye, H.O.T. (2012). Atmospheric ammonia and particulate inorganic nitrogen over the United States. Atmos. Chem. Phys. 12: 10295-10312. https://doi.org/10. 5194/acp-12-10295-2012

Holben, B.N., Eck, T.F., Slutsker, I., Tanré, D., Buis, J.P., Setzer, A., Vermote, E., Reagan, J.A., Kaufman, Y.J., Nakajima, T., Lavenu, F., Jankowiak, I. and Smirnov, A. (1998). AERONET - A Federated Instrument Network and Data Archive for Aerosol Characterization. Remote Sens. Environ. 66: 1-16. https://doi.org/10.1016/S00344257(98)00031-5

Iacono, M.J., Delamere, J.S., Mlawer, E.J., Shephard, M.W., Clough, S.A. and Collins, W.D. (2008). Radiative forcing by long-lived greenhouse gases: Calculations with the AER radiative transfer models. J. Geophys. Res. 113: D13103. https://doi.org/10.1029/2008JD009944

Karlsson, K.G., Anttila, K., Trentmann, J., Stengel, M., Meirink, J.F., Devasthale, A., Hanschmann, T., Kothe, S., Jääskeläinen, E., Sedlar, J., Benas, N., van Zadelhoff, 
G.J., Schlundt, C., Stein, D., Finkensieper, S., Håkansson, N., Hollmann, R., Fuchs, P. and Werscheck, M. (2017). CLARA-A2: CM SAF cLoud, Albedo and surface RAdiation dataset from AVHRR data - Edition 2. Satellite Application Facility on Climate Monitoring. https://doi.org/10.5676/EUM_SAF_CM/CLARA_AVH RR/V002

Kodros, J.K., Scott, C.E., Farina, S.C., Lee, Y.H., L'Orange, C., Volckens, J. and Pierce, J. R. (2015). Uncertainties in global aerosols and climate effects due to biofuel emissions. Atmos. Chem. Phys. 15: 8577-8596. https://doi.org/10.5194/acp-15-8577-2015

Kodros, J.K., Wiedinmyer, C., Ford, B., Cucinotta, R., Gan, R., Magzamen, S. and Pierce, J.R. (2016a). Global burden of mortalities due to chronic exposure to ambient $\mathrm{PM}_{2.5}$ from open combustion of domestic waste. Environ. Res. Lett. 11: 124022. https://doi.org/10.1088/1748-9326/11/1 $2 / 124022$

Kodros, J.K., Cucinotta, R., Ridley, D.A., Wiedinmyer, C. and Pierce, J.R. (2016b). The aerosol radiative effects of uncontrolled combustion of domestic waste. Atmos. Chem. Phys. 16: 6771-6784. https://doi.org/10.5194/acp16-6771-2016

Kodros, J.K. and Pierce, J.R. (2017). Important global and regional differences in aerosol cloud-albedo effect estimates between simulations with and without prognostic aerosol microphysics. J. Geophys. Res. 122: 4003-4018. https://doi.org/10.1002/2016JD025886

Kodros, J.K., Carter, E., Brauer, M., Volckens, J., Bilsback, K.R., L'Orange, C., Johnson, M. and Pierce, J.R. (2018). Quantifying the contribution to uncertainty in mortality attributed to household, ambient, and joint exposure to $\mathrm{PM}_{2.5}$ from residential solid fuel use. GeoHealth 2: 25 39. https://doi.org/10.1002/2017GH000115

Koepke, P., Hess, M., Schult, I. and Shettle, E.P. (1997). Global aerosol data set. Max-Planck-Institut für Meteorologie, Hamburg.

Liu, J., Mauzerall, D.L., Chen, Q., Zhang, Q., Song, Y., Peng, W., Klimont, Z., Qiu, X., Zhang, S., Hu, M., Lin, W., Smith, K.R. and Zhu, T. (2016). Air pollutant emissions from Chinese households: A major and underappreciated ambient pollution source. Proc. Natl. Acad. Sci. 113: 7756-7761. https://doi.org/10.1073/pnas. 1604537113

Liu, J., Kiesewetter, G., Klimont, Z., Cofala, J., Heyes, C., Schöpp, W., Zhu, T., Cao, G., Gomez Sanabria, A., Sander, R., Guo, F., Zhang, Q., Nguyen, B., Bertok, I., Rafaj, P. and Amann, M. (2019). Mitigation pathways of air pollution from residential emissions in the BeijingTianjin-Hebei region in China. Environ. Int. 125: 236244. https://doi.org/10.1016/j.envint.2018.09.059

Ma, Z., Hu, X., Huang, L., Bi, J. and Liu, Y. (2014). Estimating ground-level $\mathrm{PM}_{2.5}$ in China using satellite remote sensing. Environ. Sci. Technol. 48: 7436-7444. https://doi.org/10.1021/es5009399

Meng, W., Zhong, Q., Chen, Y., Shen, H., Yun, X., Smith, K.R., Li, B., Liu, J., Wang, X., Ma, J., Cheng, H., Zeng, E.Y., Guan, D., Russell, A.G. and Tao, S. (2019). Energy and air pollution benefits of household fuel policies in northern China. Proc. Natl. Acad. Sci. 116: 16773-16780. https://doi.org/10.1073/pnas.1904182116

National Development and Reform Commission (2017). Clean winter heating plan for Northern China (20172021).

Nethery, R.C. and Dominici, F. (2019). Estimating pollutionattributable mortality at the regional and global scales: Challenges in uncertainty estimation and causal inference. Eur. Heart J. 40: 1597-1599. https://doi.org/10.1093/eur heartj/ehz200

Ramnarine, E., Kodros, J.K., Hodshire, A.L., Lonsdale, C.R., Alvarado, M.J. and Pierce, J.R. (2019). Effects of near-source coagulation of biomass burning aerosols on global predictions of aerosol size distributions and implications for aerosol radiative effects. Atmos. Chem. Phys. 19: 6561-6577. https://doi.org/10.5194/acp-19-65612019

Rap, A., Scott, C.E., Spracklen, D.V., Bellouin, N., Forster, P.M., Carslaw, K.S., Schmidt, A. and Mann, G. (2013). Natural aerosol direct and indirect radiative effects. Geophys. Res. Lett. 40: 3297-3301. https://doi.org/10.100 2/grl.50441

Scott, C.E., Rap, A., Spracklen, D.V., Forster, P.M., Carslaw, K.S., Mann, G.W., Pringle, K.J., Kivekäs, N., Kulmala, M., Lihavainen, H. and Tunved, P. (2014). The direct and indirect radiative effects of biogenic secondary organic aerosol. Atmos. Chem. Phys. 14: 447-470. https://doi.org/10.5194/acp-14-447-2014

Shen, G., Ru, M., Du, W., Zhu, X., Zhong, Q., Chen, Y., Shen, H., Yun, X., Meng, W., Liu, J., Cheng, H., Hu, J., Guan, D. and Tao, S. (2019). Impacts of air pollutants from rural Chinese households under the rapid residential energy transition. Nat. Commun. 10: 3405. https://doi.org/ 10.1038/s41467-019-11453-w

Sinyuk, A., Dubovik, O., Holben, B., Eck, T.F., Breon, F.M., Martonchik, J., Kahn, R., Diner, D.J., Vermote, E.F., Roger, J.C., Lapyonok, T. and Slutsker, I. (2007). Simultaneous retrieval of aerosol and surface properties from a combination of AERONET and satellite data. Remote Sens. Environ. 107: 90-108. https://doi.org/10.1016/j.rse. 2006.07.022

Smirnov, A., Holben, B.N., Eck, T.F., Dubovik, O. and Slutsker, I. (2000). Cloud-screening and quality control algorithms for the AERONET database. Remote Sens. Environ. 73: 337-349. https://doi.org/10.1016/S00344257(00)00109-7

Stanaway, J.D., Afshin, A., Gakidou, E., Lim, S.S., Abate, D., Abate, K.H., Abbafati, C., Abbasi, N., Abbastabar, H., Abd-Allah, F., Abdela, J., Abdelalim, A., Abdollahpour, I., Abdulkader, R.S., Abebe, M., Abebe, Z., Abera, S.F., Abil, O.Z., Abraha, H.N., ... Murray, C.J.L. (2018). Global, regional, and national comparative risk assessment of 84 behavioural, environmental and occupational, and metabolic risks or clusters of risks for 195 countries and territories, 1990-2017: A systematic analysis for the Global Burden of Disease Study 2017. Lancet 392: 1923 1994. https://doi.org/10.1016/S0140-6736(18)32225-6

Stocker, T.F., Qin, D., Plattner, G.K., Tignor, M.M.B., Allen, S.K., Boschung, J., Nauels, A., Xia, Y., Bex, V. 
and Midgley, P.M. (2013). Climate Change 2013: The Physical Science Basis. Contribution of Working Group I to the Fifth Assessment Report of the Intergovernmental Panel on Climate Change. Cambridge University Press, Cambridge, United Kingdom and New York, NY, USA.

Streets, D.G., Gupta, S., Waldhoff, S.T., Wang, M.Q., Bond, T.C. and Yiyun, B. (2001). Black carbon emissions in China. Atmos. Environ. 35: 4281-4296. https://doi.org/10. 1016/S1352-2310(01)00179-0

The International GEOS-Chem User Community (2018). geoschem/geos-chem: GEOS-Chem 12.0.3. Zenodo. https://doi.org/10.5281/zenodo.1464210

Trivitayanurak, W., Adams, P.J., Spracklen, D.V. and Carslaw, K.S. (2008). Tropospheric aerosol microphysics simulation with assimilated meteorology: Model description and intermodel comparison. Atmos. Chem. Phys. 8: 3149 3168. https://doi.org/10.5194/acp-8-3149-2008

van Donkelaar, A., Martin, R.V., Li, C. and Burnett, R.T. (2019). Regional estimates of chemical composition of fine particulate matter using a combined geosciencestatistical method with information from satellites, models, and monitors. Environ. Sci. Technol. 53: 25952611. https://doi.org/10.1021/acs.est.8b06392

Wang, Y., Yao, L., Wang, L., Liu, Z., Ji, D., Tang, G., Zhang, J., Sun, Y., Hu, B. and Xin, J. (2014). Mechanism for the formation of the January 2013 heavy haze pollution episode over central and eastern China. Sci. China Earth Sci. 57: 14-25. https://doi.org/10.1007/s114 30-013-4773-4

Westervelt, D.M., Pierce, J.R. and Adams, P.J. (2014). Analysis of feedbacks between nucleation rate, survival probability and cloud condensation nuclei formation. Atmos. Chem. Phys. 14: 5577-5597. https://doi.org/10.51 94/acp-14-5577-2014

Xue, Y., Zhou, Z., Nie, T., Wang, K., Nie, L., Pan, T., Wu,
X., Tian, H., Zhong, L., Li, J., Liu, H., Liu, S. and Shao, P. (2016). Trends of multiple air pollutants emissions from residential coal combustion in Beijing and its implication on improving air quality for control measures. Atmos. Environ. 142: 303-312. https://doi.org/10.1016/j. atmosenv.2016.08.004

Zhang, Y.L. and Cao, F. (2015). Fine particulate matter $\left(\mathrm{PM}_{2.5}\right)$ in China at a city level. Sci. Rep. 5: 14884. https://doi.org/10.1038/srep14884

Zhang, Y.L., Huang, R.J., El Haddad, I., Ho, K.F., Cao, J.J., Han, Y., Zotter, P., Bozzetti, C., Daellenbach, K.R., Canonaco, F., Slowik, J.G., Salazar, G., Schwikowski, M., Schnelle-Kreis, J., Abbaszade, G., Zimmermann, R., Baltensperger, U., Prévôt, A.S.H. and Szidat, S. (2015). Fossil vs. non-fossil sources of fine carbonaceous aerosols in four Chinese cities during the extreme winter haze episode of 2013. Atmos. Chem. Phys. 15: 12991312. https://doi.org/10.5194/acp-15-1299-2015

Zhang, Z., Wang, W., Cheng, M., Liu, S., Xu, J., He, Y. and Meng, F. (2017). The contribution of residential coal combustion to $\mathrm{PM}_{2.5}$ pollution over China's BeijingTianjin-Hebei region in winter. Atmos. Environ. 159: 147161. https://doi.org/10.1016/j.atmosenv.2017.03.054

Zheng, B., Tong, D., Li, M., Liu, F., Hong, C., Geng, G., Li, H., Li, X., Peng, L., Qi, J., Yan, L., Zhang, Y., Zhao, H., Zheng, Y., He, K. and Zhang, Q. (2018). Trends in China's anthropogenic emissions since 2010 as the consequence of clean air actions. Atmos. Chem. Phys. 18: 14095-14111. https://doi.org/10.5194/acp-18-14095-2018

Received for review, November 6, 2019 Revised, July 2, 2020 Accepted, August 26, 2020 